\title{
Descriptions of two new Vietomartyria species (Lepidoptera, Micropterigidae) from China
}

\author{
Cheng-Qing LIAO ${ }^{1}$, Toshiya HIROWATARI ${ }^{2}$ \& Guo-Hua HUANG ${ }^{3, *}$ \\ ${ }^{1,3}$ Hunan Provincial Key Laboratory for Biology and Control of Plant Diseases and Insect Pests, \\ Hunan Agricultural University, Changsha, Hunan 410128, P.R. China. \\ ${ }^{1,3}$ College of Plant Protection, Hunan Agricultural University, Changsha, Hunan 410128, P.R. China. \\ ${ }^{2}$ Entomological Laboratory, Kyushu University, Faculty of Agriculture, 744 Motooka, \\ Nishi-ku, Fukuoka 819-0395, Japan. \\ "Corresponding author: ghhuang@hunau.edu.cn \\ 1Email:913258510@qq.com \\ 2Email: hirowat_t@agr.kyushu-u.ac.jp \\ ${ }^{1}$ urn:lsid:zoobank.org:author:373D4683-C594-4DE8-B717-E9A97478F534 \\ ${ }^{2}$ urn:lsid:zoobank.org:author:E252B891-0353-4F5F-B58A-D06AAB7CC253 \\ ${ }^{3}$ urn:1sid:zoobank.org:author:1433C74D-7C72-47F2-9072-D6325D84DD95
}

\begin{abstract}
Micropterigidae is a family of Lepidoptera characterized by plesiomorphic morphological characters. Presently, this family consists of more than 22 genera and is distributed throughout all biogeographic realms. Vietomartyria Hashimoto \& Mey, 2000 presently consists of six species mainly from South China. Two new species of the genus, $V$. wuyunjiena sp. nov. and $V$. maoershana sp. nov., are described herein from China; adult genitalia and wing venation are illustrated. Some biological accounts of the new species are also provided. A key to all described Vietomartyria species is given.
\end{abstract}

Keywords. Micropterigidae, Vietomartyria, new species, morphology, taxonomy.

Liao C.Q., Hirowatari T. \& Huang G.H. 2020. Descriptions of two new Vietomartyria species (Lepidoptera, Micropterigidae) from China. European Journal of Taxonomy 610: 1-14. https://doi.org/10.5852/ejt.2020.610

\section{Introduction}

The family Micropterigidae Herrich-Schäffer, 1855 consists of more than 160 species in 20 extant genera worldwide (van Nieukerken et al. 2011; Imada \& Kato 2018). The micropterigids form a sister clade to all the other families of the extant Lepidoptera (Kristensen et al. 2007; Regier et al. 2015). The adults are devoid of proboscis and instead possess well developed functional mandibles, by that they are regarded as a plesiomorphic group of moths together with the other non-glossatan moth families Agathiphagidae and Heterobathmiidae (Kristensen 1984, 1999). Micropterigidae are easily distinguished from the other non-glossatans by the following combiantion of characters: ocelli present; spur formula of 0:0:4; Sc vein of forewing forked; and pterostigma absent (Kristensen 1984, 1999; Hashimoto 2006). Although the biology of micropterigids is underexplored, food sources of the larvae of some species are known. 
Typically the micropterigid larvae feed on liverworts (Tillyard 1922; Tuskes \& Smith 1984; Yasuda \& Hashimoto 1989; Hashimoto 2006; Imada et al. 2011; Davis \& Landry 2012), and less commonly, on decayed plants (Carter \& Dugdale 1982), or on fresh photosynthetic angiosperm tissues (Erenler \& Gillman 2010). The adults of some species of the genera Sabatinca Walker, 1863 and Micropterix Hübner, 1825 feed either on pollens of angiosperms or spores of ferns (Zeller-Lukashort 2007; Gibbs 2010, 2014; Erenler \& Gillman 2010; Davis \& Landry 2012).

The genus Vietomartyria was established by Hashimoto \& Mey (2000) with Paramartyria expeditionis Mey, 1997 from Vietnam as the type species, based on the long basal stalk of each flagellomere and the position of the gonopore opening. Some additional distinguishing characters of Vietomartyria are: the large number of flagellum segments, more than 55 in males and 42 in females; foretibial epiphysis absent; primary R fork of forewing equal or more distal to the Sc fork; posterior margin of segment IX expanded ventro-posteriorly in male genitalia; and signum absent in female genitalia (Hashimoto \& Mey 2000). Hirowatari et al. (2009) described two new species of Vietomartyria from South China of which females have a signum in the corpus bursae and considered that the absence of a signum in the female may be unique to $V$. expeditionis. Subsequently, Hirowatari et al. (2010) added one new species, $V$. gladiator Hirowatari \& Huang, 2010 from South China and transferred two species of Paramartyria Issiki, 1931, P. jinggangna Yang, 1980 and P. baishanzuna Yang, 1995, to this genus. To date, six Vietomartyria species have been recorded, of which five species are distributed in South China (Guangdong, Jiangxi, Zhejiang). In this paper, two new Vietomartyria species are described from Hunan and Guangxi, South China.

\section{Material and methods}

Adult specimens were collected in Wuyunjie National Nature Reserve, Hunan Province and Mao'ershan National Nature Reserve, Guangxi Province, China and the wings were spread. Male and female genitalia were dissected after maceration in $10 \% \mathrm{NaOH}$ solution heated in a waterbath, and preserved in glycerol after scales were removed. The wings were treated using the same methods. The photos of adults were taken using a Leica S8APO microscope and Leica DFC435 with LAS v4.9 software. The photos of male and female genitalia and wings were taken with a ZEISS Axio Vert.A1 inverted microscope. Terminology for adults and genitalia used in this paper follows Hashimoto \& Mey (2000), Hirowatari et al. (2009) and Davis \& Landry (2012). All studied materials are deposited in Hunan Agricultural University, China (HUNAU).

\section{Results}

Class Insecta Linnaeus, 1758

Order Lepidoptera Linnaeus, 1758

Superfamily Micropterigoidea Herrich-Schäffer, 1855

Family Micropterigidae Herrich-Schäffer, 1855

Genus Vietomartyria Hashimoto \& Mey, 2000

Vietomartyria wuyunjiena sp. nov. urn:1sid:zoobank.org:act:9A2480D0-2ADB-4050-BF44-62F620AD14B7

Figs 1A, C-F, 2A, 3A-F, 5A-C

\section{Diagnosis}

The adults of this species are very similar to Vietomartyria nankunshana Hirowatari \& Hashimoto, 2009 and $V$. nanlingana Hirowatari \& Jinbo, 2009 because of their same ground color, but are separable from these two species by the dorsal process of the valva slightly curved inwardly (but almost right-angularly 
curved inwardly in $V$. wuyunjiena sp. nov.), and by tergite $\mathrm{X}$ slightly emarginate at the middle (but broadly emarginate in $V$. nankunshana and narrowly in $V$. nanlingana).

\section{Etymology}

The specific epithet is derived from the name of the type locality, Wuyunjie National Nature Reserve.

\section{Type material}

\section{Holotype}

CHINA - 7 ; Hunan Province, Taoyuan County, Changde City, Wuyunjie National Nature Reserve; 21 Apr. 2019; C.Q. Liao, M.W. Liao and G.H. Huang leg.; HUNAU.

\section{Paratypes}

CHINA・19 §̊, 9 q̊; same data as for holotype; HUNAU.

\section{Description}

Forewing Length. 2.9-3.5 mm (3.0 mm in holotype).

WING EXPANSE. $6.3-7.5 \mathrm{~mm}(6.6 \mathrm{~mm}$ in holotype).

HEAD. Vertex densely covered with long piliform scales except for exposed part between compound eye and ocellus; tufts of scales yellow brown, mixed with dark brown hairs. Maxillary palpus pale yellow. Antennal scape and pedicel with dark brown hair-like scales; flagellum 58-segmented (46 segments in female), covered with dense black hairy scales.

Thorax. Tegular tufts of piliform brown scales; mesonotum densely covered with golden broad scales, possessing metallic blue luster. Legs with dark brown scales; inner surface of fore- and mid-femur and apical band of each tarsal segment yellow; fore-tibia without epiphysis, mid-tibia without spur, hindtibia with two pairs of spurs. Forewing ground color dark brown, basal $2 / 5$ with golden luster, apical $3 / 5$ with purple luster; metallic blue luster along costa; cilia brown, paler on posterior margin. Hindwing dark fuscous except costal margin with metallic blue luster, covered with slender scales on basal half and broad scales on apical half; cilia dark brown.

Wing VENATION (Fig. 2A). Forewing with humeral vein (h) present at base; Sc deeply bifurcate; R with five branches, primary $\mathrm{R}$ fork equal to $\mathrm{Sc}$ fork, $\mathrm{R}_{4}$ and $\mathrm{R}_{5}$ long stalked; $\mathrm{Sc}-\mathrm{R}$ crossvein near basal $1 / 3$ of $\mathrm{Sc}_{2}$; M with three branches; CuA with two branches, M-CuA crossvein present; CuP separate; $1 \mathrm{~A}$ and 2A fused at basal 3/5. Hindwing venation very similar to forewing venation, except Sc and R1 fused; M-CuA crossvein absent; $1 \mathrm{~A}$ fused with $\mathrm{CuP}$ basally, then independent and fused with $2 \mathrm{~A}$.

AвDOMEn. Pregenital abdomen dark brown to black, covered with glossy dark brown scales; venter paler. Genital segments dark yellowish to fuscous, covered with long fuscous scales.

Male Genitalia (Fig. 3). Ring IX and tergite X strongly sclerotized and fused (Fig. 3A-B). Dorsal part of ring IX (tegumen) short, approximately $1 / 5$ of length of ventral part (vinculum). Tergite X (uncus) short bilobed, dorsal part arched upward; paired X tergal lobes triangular with rounded apex, bearing some long setae apically. Sternum X (gnathos) well developed, strongly sclerotized, extremely extended ventrally, ventro-posterior corners hook-like, right-angularly curved laterally (Fig. 3A, C). Valva rectangular, approximately $0.9 \times$ as long as sternum IX; dorsal process slightly curved inwardly; basal inner surface with a small denticulate projection. Medial plate (juxta) oval, slightly membranous (Fig. 3B-C). Phallobase slender, approximately as long as aedeagus; phallobase with an indistinct longitudinal keel on dorsal median line at posterior $1 / 3$; aedeagus covered with a lot of serrate minute processes at basal 
$1 / 5$ to apex ventro-laterally and at $4 / 5$ to apex dorsally, with very narrow sclerites extending from basal $1 / 5$ to gonopore at both sides; gonopore opening longitudinally at $2 / 3$ to $4 / 5$ of aedeagus, bordered by radial folds (Fig. 3D-F).

Female genitalia (Fig. 5A-C). Segment IX sclerotized, short in dorsal part (approximately $2 / 5$ length of ventral part), slightly concave dorsally and laterally. Segment X and XI formed two pairs of well sclerotized lateral plates; anterior plates triangular, dorso-posterior angle slightly rounded; posterior plates irregular quadrilateral, with minute digitate projections along posterior and ventral margins.

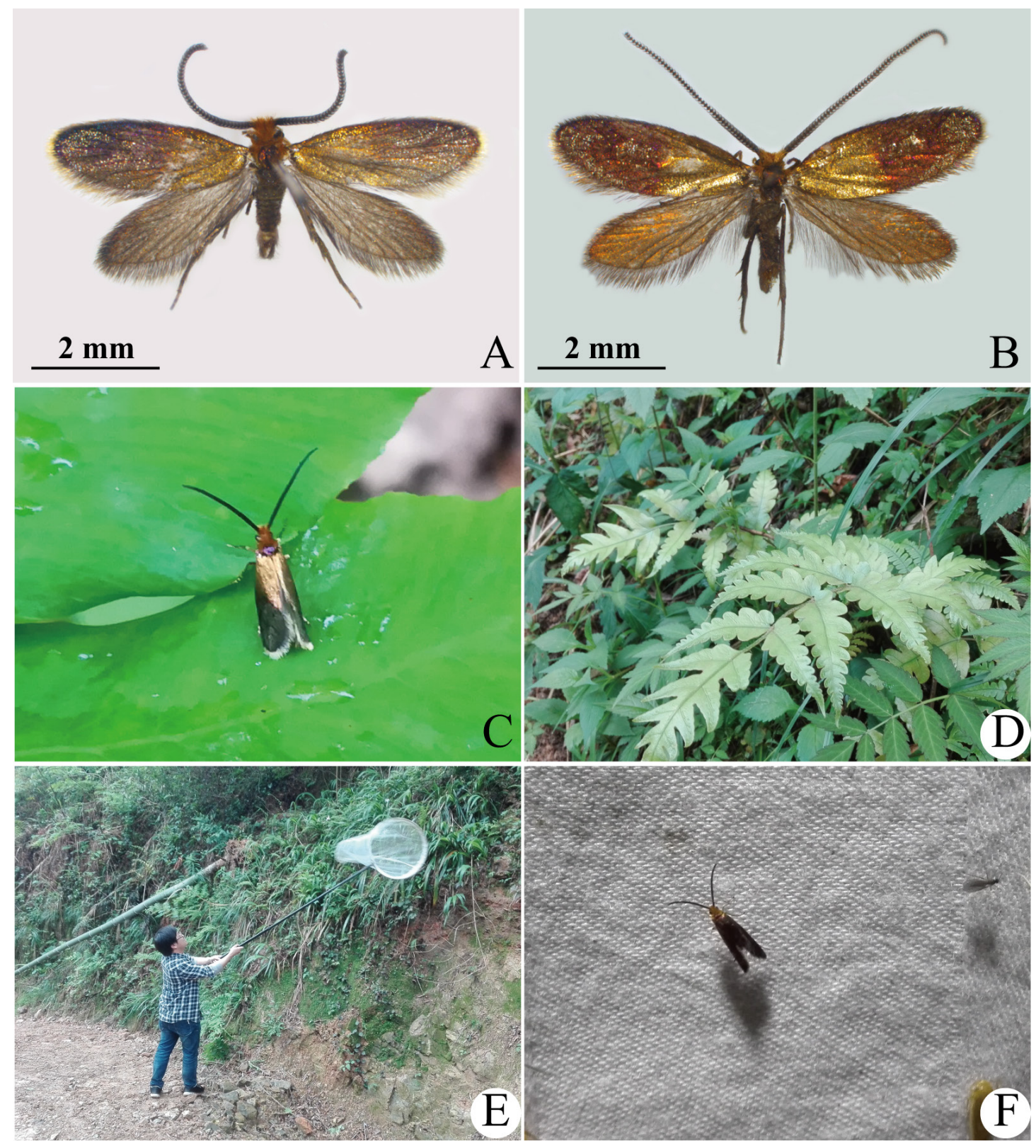

Fig. 1. Adults and habitat of Vietomartyria spp. A. Vietomartyria wuyunjiena sp. nov., holotype, ठ̊. B. Vietomartyria maoershana sp. nov., holotype, $\widehat{\delta}$. C. One adult of $V$. wuyunjiena sp. nov. perching on fern. D. Habitat of $V$. wuyunjiena sp. nov. E. Specimen collection of $V$. wuyunjiena sp. nov. by sweep net. F. One adult of $V$. wuyunjiena sp. nov. perching on the white curtain of a light trap. 
Corpus bursae membranous, elongate, apical half covered with minute wrinkles; signa with two pairs of scale-like plates with many long hairs.

\section{Immature stages}

Unknown.

\section{Distribution}

This species is known from Wuyunjie National Nature Reserve (Taoyuan, Changde, Hunan, China).
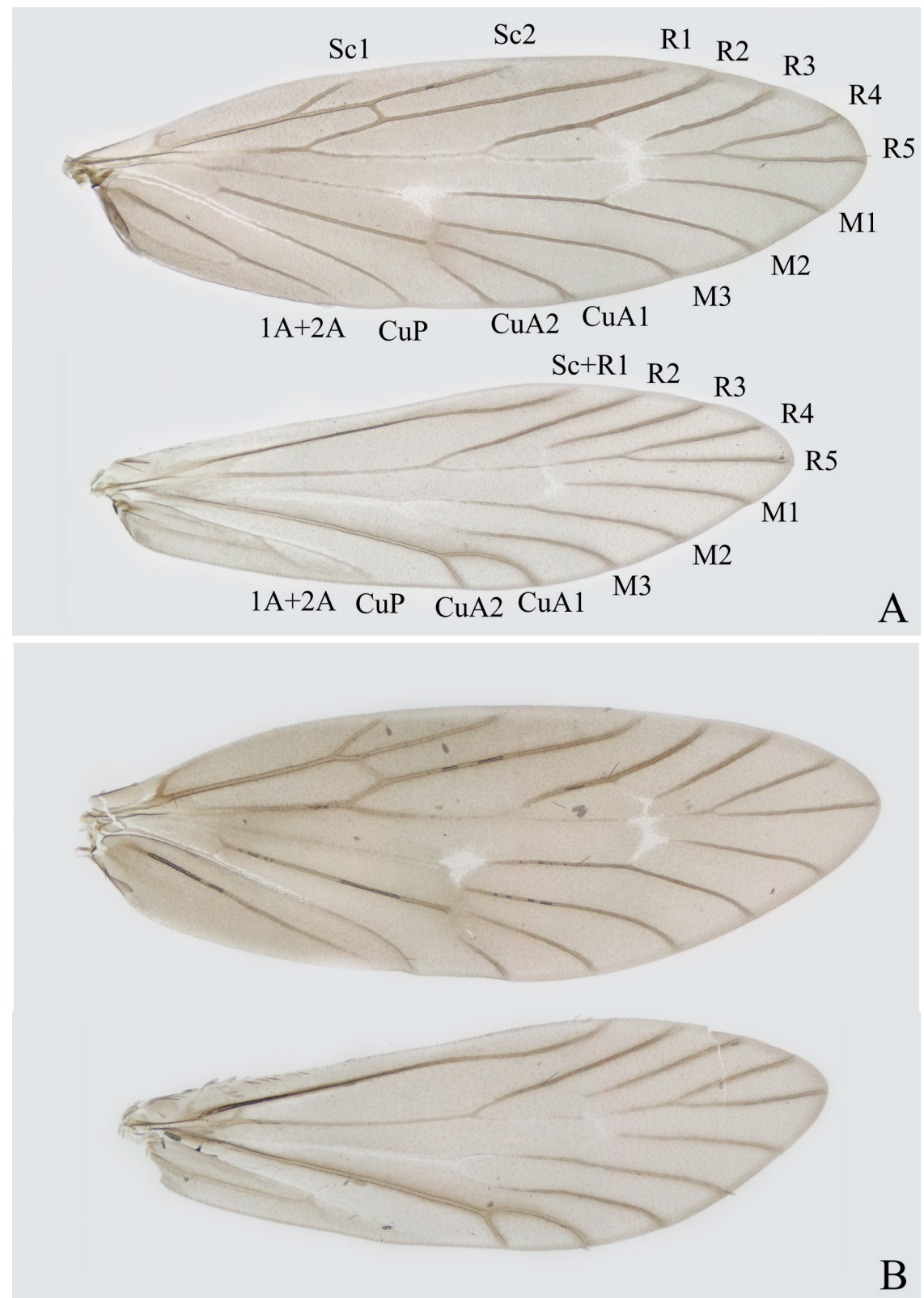

Fig. 2. Wing venation. A. Vietomartyria wuyunjiena sp. nov. ․ B. V. maoershana sp. nov. đ̊. 


\section{Remarks}

Adults of $V$. wuyunjiena sp. nov. were observed flying or perching on low shrubs and ferns along a muddy road leading to the mountain, of which the other side faces a river valley (Fig. 1C-D). It was cloudy and humid while the collections were made during 4-6 p.m. on April $21^{\text {st }} 2019$. Adults flew relatively slowly making them easy to collect with sweep nets (Fig. 1E). Unfortunately, we could not observe feeding and mating behaviors of adults, nor did we collect any specimens in immature stages. Additionally, we observed one adult attracted to a light trap at 11:30 p.m. on April $21^{\text {st }} 2019$ (Fig. 1F). The female adults of Agrionympha capensis Whalley, 1978 can also be attracted by lights at night (Gibbs \& Kristensen 2011).

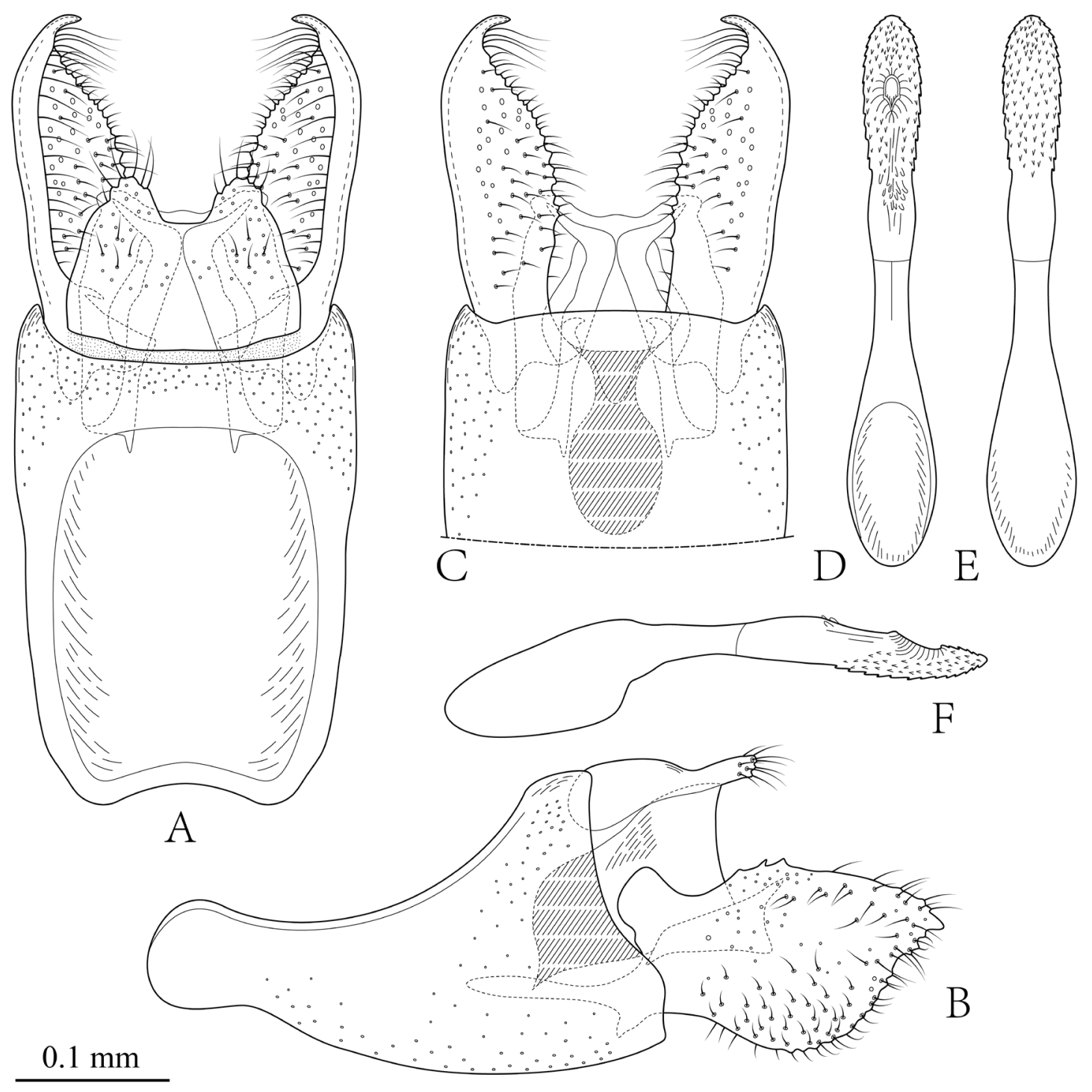

Fig. 3. Male genitalia of Vietomartyria wuyunjiena sp. nov. A. Dorsal view, with phallus removed. B. Ditto, ventral view. C. Ditto, lateral view. D. Phallus, dorsal view. E. Ditto, ventral view. F. Ditto, lateral view. 


\section{Vietomartyria maoershana sp. nov. urn:Isid:zoobank.org:act:4A00FA98-B2BA-4930-93ED-030407B3CDBD}

Figs 1B, 2B, 4A-F, 5D-F

\section{Diagnosis}

This species is very similar to $V$. wuyunjiena sp. nov. and $V$. expeditionis, but can easily be distinguished by the following characters: paired $\mathrm{X}$ tergal lobes slender and digitate (slightly emarginate in $V$. wuyunjiena sp. nov. and broadly emarginate at the middle in $V$. expeditionis); basal process of valva long and pointed (absent in $V$. wuyunjiena sp. nov. and short obtuse in $V$. expeditionis); slightly curved dorsal process of gonopod (strongly curved in $V$. expeditionis).

\section{Etymology}

This specific epithet is derived from the name of the type locality, Mao'ershan National Nature Reserve.

\section{Type material}

\section{Holotype}

CHINA - ô; Guangxi Province, Xin'an County, Guilin City, Mao'ershan National Nature Reserve; 1500 m a.s.1.;25-26 May 2010; T. Hirowatari and G.H. Huang leg.; HUNAU.

\section{Paratypes}

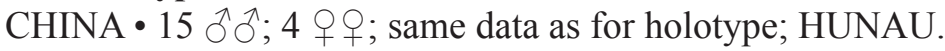

\section{Description}

FOREWING LENGTH. 3.0-3.3 mm (3.1 mm in holotype).

WING EXPANSE. 6.6-7.1 $\mathrm{mm}$ (6.7 $\mathrm{mm}$ in holotype).

HEAD. Vertex densely covered with long piliform scales except for an exposed part between compound eye and ocellus; tufts of scales yellow to brown, mixed with dark brown hairs. Maxillary palpus pale yellow. Antennal scape and pedicel with pale brown hair-like scales; flagellum 58-segmented (46 segments in female), covered with dense black hairy scales, some basal segments with somewhat metallic blue luster.

THORAX. Tegular tufts of piliform brown scales; mesonotum with dense golden scales which possess metallic blue luster. Legs with black scales; inner surface of fore- and mid-femur yellow; fore-tibia without epiphysis, mid-tibia without spur, hind-tibia with two pairs of spurs. Forewing ground color yellow, basal $2 / 5$ with golden luster, apical $3 / 5$ with blue and purple luster; cilia dark brown, paler on posterior margin. Hindwing pale fuscous, covered with slender scales on basal half and broad golden scales on apical half; cilia dark brown.

Wing VenATIOn (Fig. 2B). Very similar to $V$. wuyunjiena sp. nov., but Sc-R crossvein near Sc fork, about $1 / 9$ of $\mathrm{Sc}_{2}, \mathrm{R}_{4}$ and $\mathrm{R}_{5}$ relatively short stalked, and $2 \mathrm{~A}$ almost absent in forewing.

ABdomen. Pregenital abdomen fuscous, covered with dark fuscous scales; venter paler. Genital segments dark gray to fuscous, covered with long fuscous scales.

Male Genitalia (Fig. 4). Ring IX and tergite X strongly sclerotized and fused (Fig. 4A). Dorsal part of ring IX (tegumen) short, approximately $1 / 8$ of length of ventral part (vinculum). Tergite X (uncus) deeply bilobed, dorsal part slightly arched upward; paired X tergal lobes slender digitate, bearing some long setae apically. Sternum X (gnathos) well developed, strongly sclerotized, extremely extended ventrally (Fig. 4C-D). Valva sclerotized, approximately $0.8 \times$ as long as sternum IX; dorsal process slightly 
curved inwardly; basal inner surface expanding dorsally, with a long pointed arcuate projection near dorsal part (Fig. 4B). Medial plate (juxta) extended, with an oblong apex, slightly sclerotized (Fig. 4A). Phallobase slender, approximately as long as aedeagus; aedeagus covered with a lot of serrate minute processes at basal $1 / 4$ to apex ventro-laterally and at $1 / 3$ to apex dorsally, with very narrow sclerites extending from base to gonopore at both sides; gonopore opening longitudinally at dorsal $1 / 2$ to $3 / 4$ of aedeagus, bordered by radial folds (Fig. 4E-F).

Female genitalia (Fig. 5C-D). Segment IX sclerotized, short in dorsal part (approximately $1 / 3$ length of ventral part), slightly concave laterally. Segment $X$ with a pair of triangular, well sclerotized lateral plates with broad digitate projections along apical half margin, and densely covered with minute spines on basal half ventrally. Corpus bursae membranous, oval, apical half covered with minute wrinkles; signa with two pairs of rhombus-shaped plates with many long hairs.

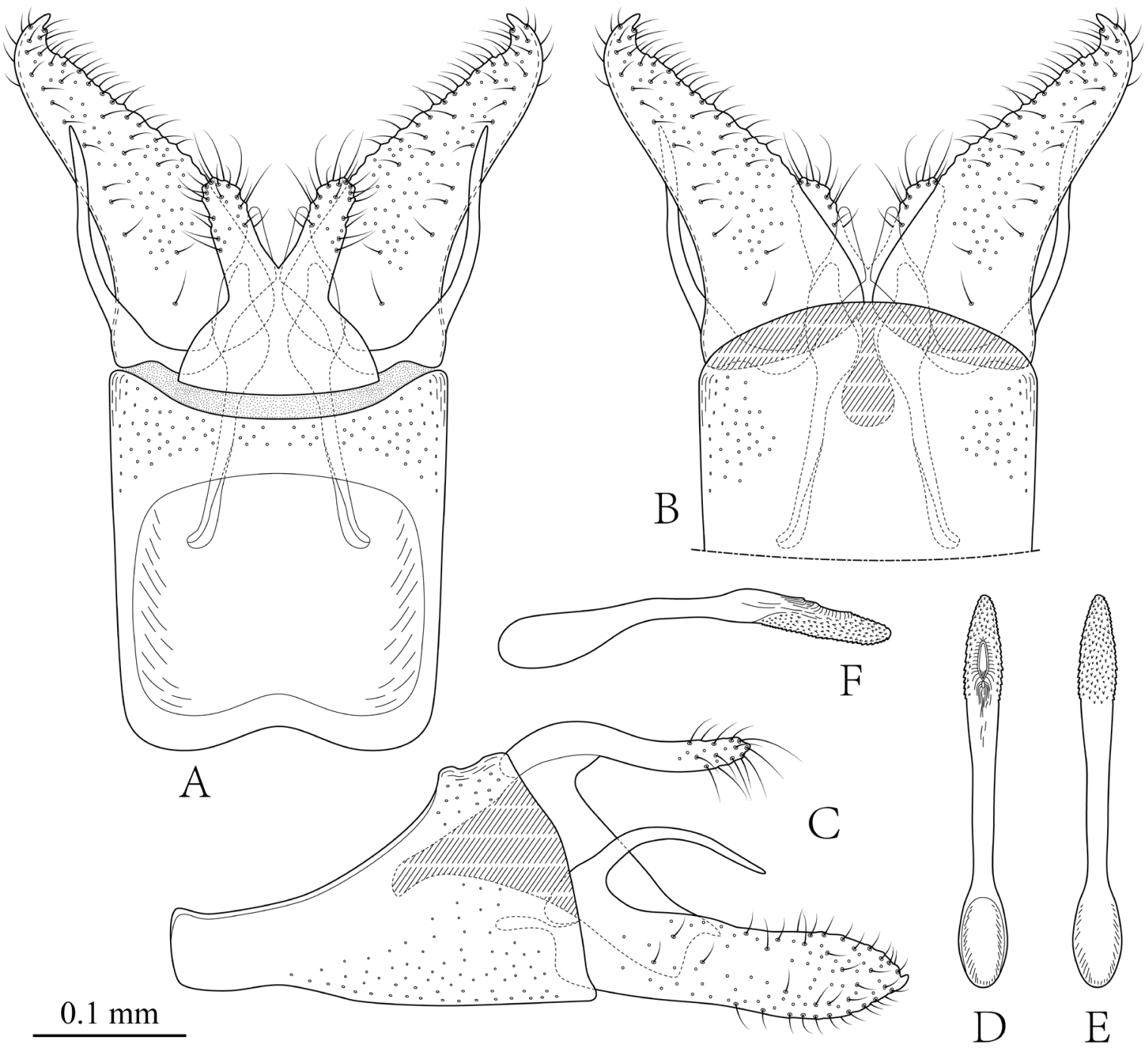

Fig. 4. Male genitalia of Vietomartyria maoershana sp. nov. A. Dorsal view, with phallus removed. B. Ditto, ventral view. C. Ditto, lateral view. D. Phallus, dorsal view. E. Ditto, ventral view. F. Ditto, lateral view. 


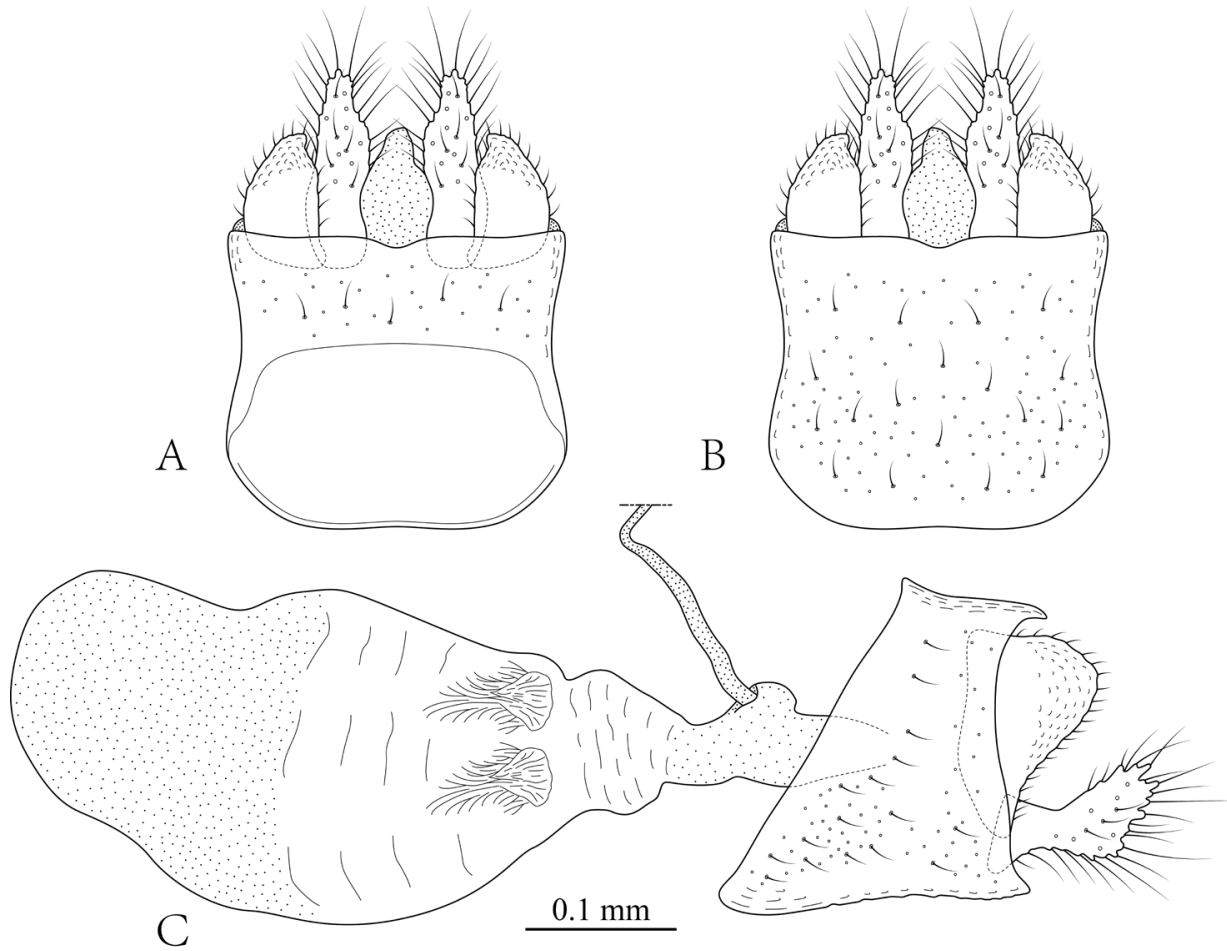

C
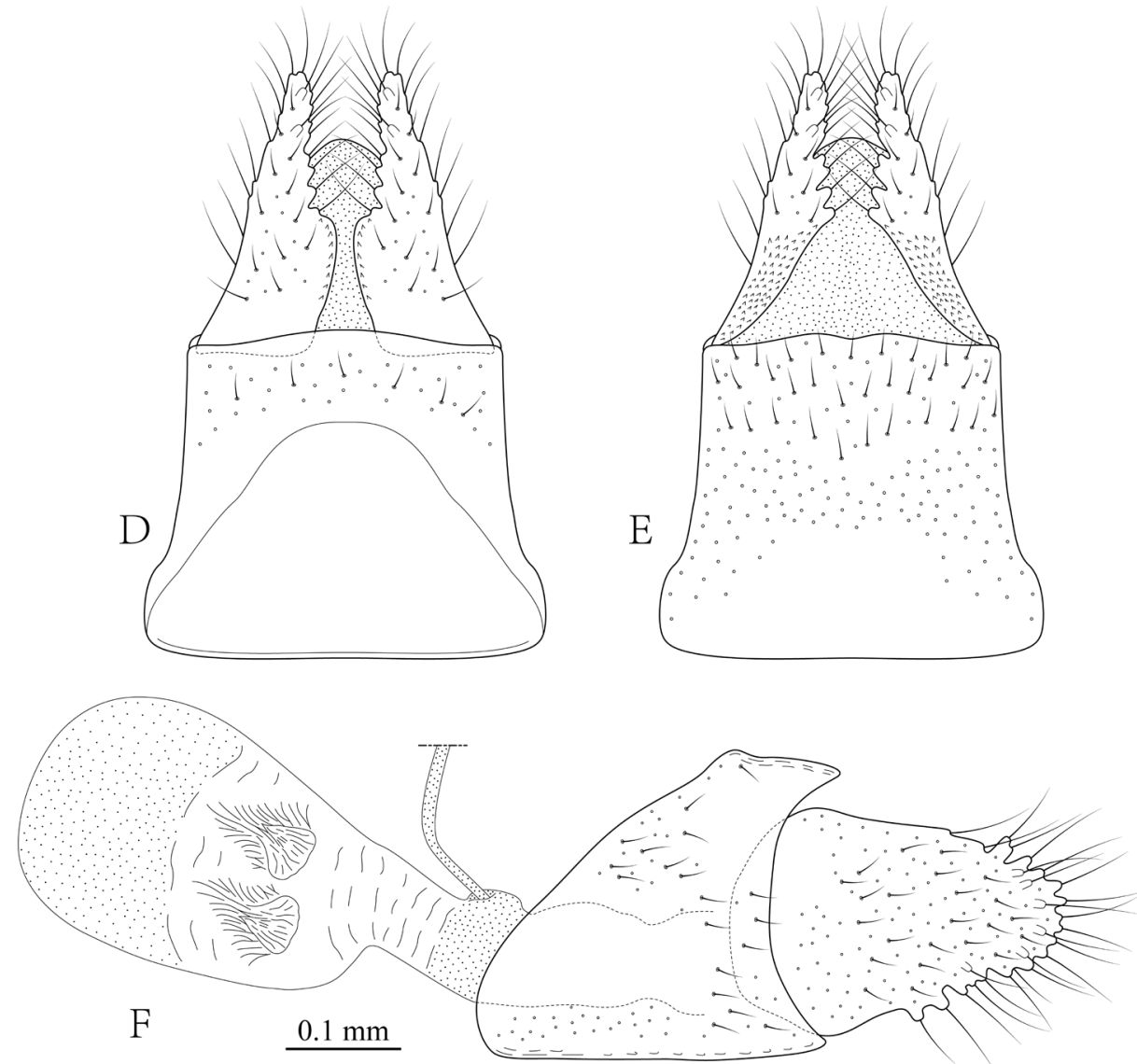

Fig.5. Female genitalia of Vietomartyria spp. A-C. Vietomartyria wuyunjiena sp. nov. D-F. V. maoershana sp. nov. A, D. Terminalia, dorsal view. B, E. Ditto, ventral view. C, F. Terminalia and bursa copulatrix, lateral view. 


\section{Immature stages}

Unknown.

\section{Distribution}

This species is known from Mao'ershan National Nature Reserve (Xin'an, Guilin, China).

\section{Remarks}

Adults of $V$. maoershana sp. nov. were collected along a paved road at $1500 \mathrm{~m}$ a.s.1., half way up Mt Mao'ershan. Similar to $V$. wuyunjiena sp. nov., the adults were observed flying or perching on low shrubs and ferns in cloudy conditions and even in weak rainfall.

\section{Key to species of the genus Vietomartyria}

1. Forewing with broad golden stria at basal $1 \frac{1}{3}$; tergite $X$ (uncus) semicircular with an emarginate spine at middle posteriorly V. gladiator Hirowatari \& Huang, 2010

- Forewing with golden luster at basal half and purple luster apically; tergite $\mathrm{X}$ bilobed, formed paired $\mathrm{X}$ tergal lobes

2. Dorsal process of valva right-angularly curved inwardly, with a long pointed apex 3

- Dorsal process of valva more or less curved inwardly, but not right-angular, with an obtuse or small apex

3. Tergite $\mathrm{X}$ horizontal dorsally, paired $\mathrm{X}$ tergal lobes slender digitate

V. nanlingana Hirowatari \& Jinbo, 2009

- Tergite X curved ventrally, paired X tergal lobes broad, triangular

4. Basal inner surface of valva expanding dorsally, with a long hooked projection near dorsal part ..... V. nankunshana Hirowatari \& Hashimoto, 2009

- Basal inner surface of valva not expanding dorsally, without a hooked projection near dorsal part ....

5. Basal half of valva longer than width

V. jinggangana (Yang, 1980)

- Basal half of valva distinctly wider than long V. baishanzuna (Yang, 1995)

6. Dorsal process of valva broad, overtly curved inwardly

- Dorsal process of valva small, slightly curved inwardly

V. expeditionis (Mey, 1997)

7. Tergite $X$ deeply bilobed, paired $X$ tergal lobes digitate; basal inner surface of valva with a long pointed arcuate projection near dorsal part V. maoershana sp. nov.

- Tergite X shallowly bilobed, paired X tergal lobes triangular; basal inner surface of valva without a long pointed projection near dorsal part V. wuyunjiena sp. nov.

\section{Discussion}

In this study, we add two new species of Vietomartyria from China based on the distinguishing characters defined by Hashimoto \& Mey (2000) and Hirowatari et al. (2009): i) each flagellomere with long basal stalk; ii) aedeagus with many minute serrate projections near gonopore; iii) gonopore situated dorsally near apex. Additionally, we provide a distribution map (Fig. 6) of all known species of Vietomartyria.

Among eight species of Vietomartyria, V. gladiator is unique in that it lacks the dorsal projection of the gonopod (valva) (Hirowatari et al. 2010). Furthermore, several other autapomorphic characters of 
$V$. gladiator make it possible to distinguish this species from other species, such as non-bilobed tergite $\mathrm{X}$ (while bilobed in other species), prominent sword-like process of anal cone sclerite (extending lateroventrally but not distinct beyond tergite $\mathrm{X}$ ), and type and position of the gonopore. The female genitalia are similar to $V$. expeditionis in the absence of signa, but it seems to be a homoplastic condition (i.e., secondary loss). In the present study, we also found a characteristic feature of $V$. wuyunjiena sp. nov., whereby segments $\mathrm{X}+\mathrm{XI}$ of the female are not fused into a pair of lateral plates as in other species, but form two pairs. In addition, $V$. gladiator apparently differs in habitat compared to other species: this species lives in moist habitats along a stream in a valley in Mt Nankunshan, Guangdon (Hirowatari et al. 2010), whereas the other species (e.g., V. nankunshana, $V$. nanlingana, $V$. wuyunjiena sp. nov. and $V$. maoershana sp. nov.) live in comparatively drier habitats such as exposed lower shrubs, weeds and ferns along mountain road-sides. The differences of habitats between these two groups may reflect differences in their host-plant uses. This study contributes to filling a knowledge gap in the diversity of micropterigids in China. To clarify the phylogenetic position of the genus, specimens of Vietomartyria should be examined based on morphological and molecular data and compared to some closely related genera (e.g., Paramartyria). Kristensen (1997) hypothesized that liverwort-feeding is a plesiomorphic feeding habit of Lepidoptera. As it is shown that most species of micropterigids in Japan feed on a single liverwort species (Imada et al. 2011), species of Vietomartyria may also be associated with some specific groups of liverworts. Elucidating the immature stages, particularly identifying their host plants, will give us insights into the evolution of host-plant use.

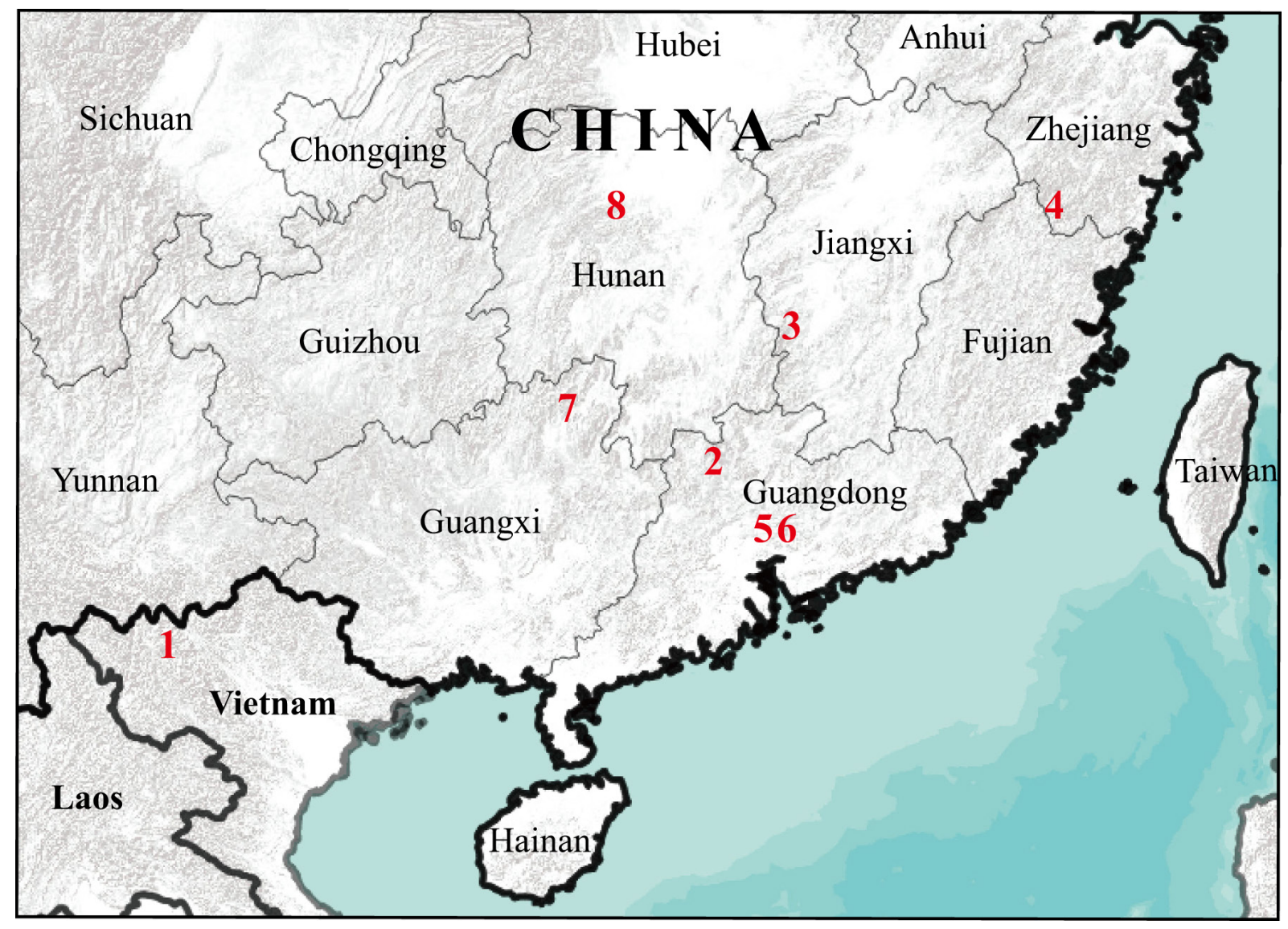

Fig. 6. Distribution of Vietomartyria spp. $1=V$. expeditionis (Mey, 1997); $2=V$. nanlingana Hirowatari \& Jinbo, 2009; $3=V$. jinggangana (Yang, 1980); $4=V$. baishanzuna (Yang, 1995); $5=V$. nankunshana Hirowatari \& Hashimoto, 2009; $6=$ V. gladiator Hirowatari \& Huang, 2010; $7=$ V. maoershana sp. nov.; $8=V$. wuyunjiena sp. nov. 


\section{Acknowledgments}

The authors thank Dr Min Wang (South China Agricultural University, China), Mr Ming-Wei Liao (Hunan Agricultural University, China), Mr Wen-Wei Zhang, Mr Min Wang and Mr Ming-Jian Wang (Hunan Wuyunjie National Nature Reserve Administration) for their help on collection in the field. The authors also thank Yume Imada (Ehime University, Japan) for her careful reading of our manuscript and for many constructive comments. This study was supported by the Biodiversity Survey and Assessment Project of the Ministry of Ecology and Environment, China (2019HJ2096001006), JSPS and NSFC under the Japan-China Scientific Cooperation Program, and JSPS KAKENHI Grant Number JP16H05766, and Double first-class construction project of Hunan Agricultural University.

\section{References}

Carter D.J. \& Dugdale J.S. 1982. Notes on collecting and rearing Micropterix (Lepidoptera: Micropterigidae) larvae in England. Entomologist's Gazette 33: 43-47.

Davis D.R. \& Landry J. 2012. A review of the North American genus Epimartyria (Lepidoptera, Micropterigidae) with a discussion of the larval plastron. ZooKeys 183: 37-83. https://doi.org/10.3897/zookeys.183.2556

Erenler H.E. \& Gillman M.P. 2010. Synchronisation of adult activity of the archaic moth, Micropterix calthella L. (Lepidoptera, Micropterigidae), with anthesis of sedges (Carex spp., Cyperaceae) in an ancient wood. Arthropod-Plant Interactions 4 (2): 117-128. https://doi.org/10.1007/s11829-010-9090-7

Gibbs G.W. 2010. Micropterigidae (Lepidoptera) of the Southwestern Pacific: a revision with the establishment of five new genera from Australia, New Caledonia and New Zealand. Zootaxa 2520: 1-48. https://doi.org/10.11646/zootaxa.2520.1.1

Gibbs G.W. 2014. Micropterigidae (Insecta: Lepidoptera). Fauna of New Zealand 72, Manaaki Whenua Press, Lincoln, New Zealand. https://doi.org/10.7931/J2/FNZ.72

Gibbs G.W. \& Kristensen N.P. 2011. Agrionympha, the long-known South African jaw moths: a revision with descriptions of new species (Lepidoptera, Micropterigidae). Zootaxa 2764: 1-21.

https://doi.org/10.11646/zootaxa.2764.1.1

Hashimoto S. 2006. A taxonomic study of the family Micropterigidae (Lepidoptera, Micropterigoidea) of Japan, with the phylogentic relationships among the Northern Hemisphere genera. Bulletin of the Kitakyushu Mususeum of Natural History and Human History, Series A 4: 39-109.

Hashimoto T. \& Mey W. 2000. Establishment of a new genus Vietomartyria (Lepidoptera, Micropterigidae) for Paramartyria expeditionis Mey. Transactions of the Lepidopterological Society of Japan 52: 37-44.

Hirowatari T., Hashimoto S., Jinbo U. \& Wang M. 2009. Descriptions of two new species of Vietomartyria Hashimoto \& Mey (Lepidoptera, Micropterigidae) from South China, with reference to autapomorphies of the genus. Entomological Science 12: 67-73. https://doi.org/10.1111/j.1479-8298.2009.00305.x

Hirowatari T., Huang G.H., Hashimoto S. \& Wang M. 2010. A remarkable new species of Vietomartyria Hashimoto \& Mey (Lepidoptera, Micropterigidae) from South China. Transactions of the Lepidopterological Society of Japan 61 (3): 211-217.

Imada Y. \& Kato M. 2018. Descriptions of new species of Issikiomartyria (Lepidoptera, Micropterigidae) and a new genus Melinopteryx gen. n. with two new species from Japan. Zoosystematics and Evolution 94 (2): 211-235. https://doi.org/10.3897/zse.94.13748

Imada Y., Kawakita A. \& Kato M. 2011. Allopatric distribution and diversification without niche shift in a bryophyte-feeding basal moth lineage (Lepidoptera: Micropterigidae). Proceedings of the Royal Society B: Biological Sciences 278: 3026-3033. https://doi.org/10.1098/rspb.2011.0134 
Kristensen N.P. 1984. Studies on the morphology and systematics of primitive Lepidoptera (Insecta). Steenstrupia 10 (5): 141-191.

Kristensen N.P. 1997. Early evolution of the Lepidoptera + Trichoptera lineage: phylogeny and the ecological scenario. In: Grandcolas P. (ed.) The Origin of Biodiversity in Insects: Phylogenetic Tests of Evolutionary Scenarios. Mémoires du Muséum national d'histoire naturelle 173: 253-271.

Kristensen N.P. 1999. The non-Glossatan Moths. Ch. 4. In: Kristensen N.P. (ed.) Lepidoptera, Moths and Butterflies. Volume 1: Evolution, Systematics, and Biogeography. Handbuch der Zoologie. Eine Naturgeschichte der Stämme des Tierreiches / Handbook of Zoology. A Natural History of the phyla of the Animal Kingdom. Band / Volume IV Arthropoda: Insecta Teilband / Part 35: 41-49. Walter de Gruyter, Berlin / New York.

Kristensen N.P., Scoble M.J. \& Karsholt O. 2007. Lepidoptera phylogeny and systematics: the state of inventorying moth and butterfly diversity. Zootaxa 1668: 699-747.

https://doi.org/10.11646/zootaxa.1668.1.30

Regier J.C., Mitter C., Kristensen N.P., Davis D.R., van Nieukerken E.J., Rota J., Simonsen T.J., Mitter K.T., Kawahara A.Y., Yen S.H., Cummings M.P. \& Zwick A. 2015. A molecular phylogeny for the oldest (nonditrysian) lineages of extant Lepidoptera, with implications for classification, comparative morphology and life-history evolution. Systematic Entomology 40 (4): 671-704.

https://doi.org/10.1111/syen.12129

Tillyard R.J. 1922. On the larva and pupa of the genus Sabatinca (Order Lepidoptera, Family Microterygidae). Transactions of the Entomological Society of London 70: 437-453.

https://doi.org/10.1111/j.1365-2311.1923.tb02840.x

Tuskes P.M. \& Smith N.J. 1984. The life history and behavior of Epimartyria pardella (Micropterigidae). Journal of the Lepidopterists' Society 38 (1): 40-46.

van Nieukerken E.J., Kaila L., Kitching I.J., Kristensen N.P., Lees D.C., Minet J., Mitter C., Mutanen M., Regier J.C., Simonsen T.J., Wahlberg N., Yen S.H., Zahiri R., Adamski D., Baixeras J., Bartsch D., Bengtsson B.Å., Brown J.W., Bucheli S.R., Davis D.R., de Prins J., de Prins W., Epstein M.E., GentiliPoole P., Gielis C., Hättenschwiler P., Hausmann A., Holloway J.D., Kallies A., Karsholt O., Kawahara A.Y., Koster S., Kozlov M.V., Lafontaine J.D., Lamas G., Landry J.F., Lee S., Nuss M., Park K.T., Penz C., Rota J., Schintlmeister A., Schmidt B.C., Sohn J.C., Solis M.A., Tarmann G.M., Warren A.D., Weller S., Yakovlev R.V., Zolotuhin V.V. \& Zwick A. 2011. Order Lepidoptera Linnaeus, 1758. In: Zhang Z.-Q. (ed.) Animal biodiversity: An outline of higher-level classification and survey of taxonomic richness. Zootaxa 3148: 212-221. https://doi.org/10.11646/zootaxa.3148.1.41

Yasuda T. \& Hashimoto S. 1989. On the larva of Paramartyria semifasciella Issiki (Zeugloptera, Micropterigidae). Tyô to Ga 40: 229-234. [In Japanese with English summary.]

Zeller-Lukashort H.C., Kurz M.E., Lees D.C. \& Kurz M.A. 2007. A review of Micropterix Hübner, 1825 from northern and central Europe (Micropterigidae). Nota Lepidopterologica 30: 235-298.

Manuscript received: 15 September 2019

Manuscript accepted: 18 November 2019

Published on: 2 March 2020

Topic editor: Gavin Broad

Desk editor: Pepe Fernández 
Printed versions of all papers are also deposited in the libraries of the institutes that are members of the EJT consortium: Muséum national d'histoire naturelle, Paris, France; Meise Botanic Garden, Belgium; Royal Museum for Central Africa, Tervuren, Belgium; Royal Belgian Institute of Natural Sciences, Brussels, Belgium; Natural History Museum of Denmark, Copenhagen, Denmark; Naturalis Biodiversity Center, Leiden, the Netherlands; Museo Nacional de Ciencias Naturales-CSIC, Madrid, Spain; Real Jardín Botánico de Madrid CSIC, Spain; Zoological Research Museum Alexander Koenig, Bonn, Germany; National Museum, Prague, Czech Republic. 